\title{
High transmission of leprosy among inhabitants in two former isolated leprosy villages in Senegal
}

\author{
Madoky Magatte Diop ${ }^{\mathrm{a}, \mathrm{b}}$, Lahla Fall ${ }^{\mathrm{c}}$, Pauline Diousséa, \\ Ibrahima Manée ${ }^{\text {, Hyacinthe Zoubi }}{ }^{\mathrm{f}}$, Fatou Badiane ${ }^{\mathrm{f}}$, Karl Puchner ${ }^{\mathrm{d}}$, \\ Amadou Doucoure ${ }^{\mathrm{f}}$, Mahamath Cissée ${ }^{\mathrm{e}}$ Laure Almairac ${ }^{\mathrm{d}} \&$ \\ Christa Kasang ${ }^{\mathrm{d}}$

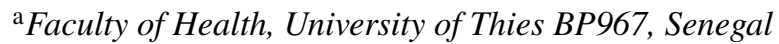 \\ ${ }^{\mathrm{b}}$ Thies Regional Hospital, Senegal \\ ${ }^{\mathrm{c}} \mathrm{CHOM}$ (The Order of Malta Hospital), Senegal \\ ${ }^{\mathrm{d}}$ DAHW (Deutsche Lepra- und Tuberkulosehilfe e.V.), Germany \\ ${ }^{\mathrm{e}}$ DAHW Senegal, Senegal \\ ${ }^{\mathrm{f}}$ Ministry for Health and Social Action of Senegal, Senegal
}

Submitted 15 September 2020; Accepted 27 November 2020

\begin{abstract}
Summary
Background: In Senegal, endemic areas of leprosy are mainly concentrated in urban settings, and transmission occurs particularly among children. This study aims to determine the prevalence of leprosy in two highly endemic foci in Senegal as well as to evaluate the association between the detection of leprosy and the family history of leprosy.

Methods: The study is a cross sectional study with cluster sampling in two former isolated leprosy villages, Mballing and Koutal. Informed consent was obtained, followed by a questionnaire and a clinical examination. The data collected included: demographics, family history of leprosy, relapse and treatment history. The analysis was done via chi-square or Fisher tests (with an agreed risk of 0.05 and a precision of $0.02)$.
\end{abstract}

Results: A total of 1605 people over 2 years of age were examined, of whom 881 were female. Children between 2 and 15 years made up 44\% (699/1605). Active leprosy was detected in 83 cases constituting a prevalence rate of 5.2\%. Overall, a total of 69 new cases were confirmed, 41 being children. The median age was 20.4 years. Of the 69 newly detected cases, $59(85.5 \%)$ were paucibacillary indicating early detection. The rate of grade 2 disability was $2.9 \%$. Altogether 36 of the new patients $(52 \%)$ had a family history of leprosy.

Conclusion: A high level of Mycobacterium leprae is circulating within the study population and transmission is ongoing. In addition to the influence of the contact profile, genetic susceptibility to leprosy could explain the high number of familial leprosy cases in these special areas, isolated for many years. Further research is needed

Correspondence to: Christa Kasang (e-mail: christa.kasang@dahw.de) 
and additional measures for leprosy control, such as post exposure prophylaxis with single dose rifampicin, should be implemented to interrupt transmission.

Keywords: Leprosy, Senegal, active case finding, contact screening, familial leprosy

\section{Background}

Leprosy has plagued humankind for over 4000 years, ${ }^{1}$ causing suffering and stigma for the world's poorest and most marginalized. More than 210,000 new cases $(16,000+$ in children) are reported annually. Despite the fact that large-scale multidrug therapy (MDT) for leprosy roll-out in the late 1980s initially led to a dramatic decrease in prevalence, no further reduction of new leprosy case notification is recognized in the past ten years. Endemic foci of infection remain throughout the world. ${ }^{2,3}$ Furthermore, the increasing lack of knowledge delays diagnosis and leads to a persistent transmission. The prevalence of leprosy in Senegal has been below the elimination threshold since 1995. In 2009, the prevalence rate was 0.48 per 10,000 , and in $2014,0.60$ per 10,000. But high leprosy endemic areas are still present, mostly concentrated in urban settings. In these critical areas transmission is particularly present among children. ${ }^{4-6}$ Isolation of leprosy diagnosed patients was mandatory in Senegal in the past, and high social stigma associated with leprosy is present up to now. Therefore, former leprosy colonies are still socially and geographically isolated, many families are affected by leprosy and migration is limited. This special circumstances can result in a genetic predisposition to leprosy. ${ }^{7}$

Several strategies for treating leprosy were implemented in Senegal, starting from traditional chaulmoogra oil treatment, dapsone monotherapy, various cocktails of antibiotics, with or without rifampicin, before finally benefiting from MDT as the recommended treatment by the World Health Organization (WHO). MDT has been applied progressively in Senegal. First in all newly screened leprosy patients, then extended to former leprosy patients still under monotherapy by dapsone, regardless of the duration of the monotherapy. With a range of $95 \%$ to $100 \%$, the completion rates of treatment have always been satisfactory.

\section{Methods}

\section{AIM OF THE STUDY}

This study aims to determine the prevalence of leprosy in two former leprosy colonies of Koutal and Mballing in Senegal and to evaluate the association between the detection of leprosy and the family history of leprosy in the two villages.

\section{STUDY DESIGN}

The study is a cross sectional study with random cluster sampling conducted in the years 2016 and 2017. It includes study participants from two former leprosy colonies, previously classified as "villages des reclassement social (VRS)". The populations of the two villages, Mballing and Koutal, are well-documented, neighborhood by neighborhood, concession by concession, with a list of households. A two-stage WHO cluster survey with the creation of 30 clusters was used. ${ }^{8}$ Replacement clusters, in the case of non-response households, were identified. The first degree of circulation is based on neighborhoods, the second degree on concessions. 


\section{STUDY SITES}

The study targeted two former leprosy colonies. These two VRS are unique in that they may result in a socio-anthropological specialty, due to isolation from the rest of the population. ${ }^{9}$ In fact, Mballing is a rural commune with 6500 inhabitants, $100 \mathrm{~km}$ away from Dakar in the region of Thies. It benefits from economic activities, with huge income potential linked to its proximity to the sea and large seaside tourist resorts within the zone, as well as a good educational system. In contrast, Koutal, $200 \mathrm{~km}$ inland in the region of Kaolack, can be described as a typical, rural village where around 1200 people live. ${ }^{10}$ Its economy relies primarily on agriculture, with major constraints linked to the poor fertility of the soil, which explains poor yields and, compared to Mballing, a very poor standard of living.

\section{STUDY PARTICIPANTS, SAMPLE SIZE}

In both villages, the resident population aged over five years was surveyed. In Koutal, 671 persons over the age of 5 years were examined. In Mballing, the sampling method enabled the recruitment of 934 persons aged 5 years or more.

The prevalence of leprosy in Mballing and Koutal was estimated at 5\%, at an estimated $95 \%$ confidence level and an accuracy of 0.02 . The minimum number of subjects required to conduct the study was 912 .

\section{ETHICAL CONSIDERATIONS}

In the two villages, the survey was rolled out after informed consent was obtained from the resident population (with the consent of their legal guardians for those aged between 5 and 15 years old). Information was collected from clinical examinations, from a questionnaire and from the district health register. The study was approved by the national ethics authority: "Avis éthique et scientifique n 103/MSAS/DPRS/CNERS en date 04/07/2016".

\section{DATA COLLECTED}

Data were collected in a standardized manner, on the basis of a questionnaire based on clinical examinations in health districts. Core points included demographic data, signs and symptoms of leprosy, diagnosis of leprosy, leprosy deformity and family history.

The screening for leprosy suspects was carried out by full body screens for lesions of all participants by trained health workers. The clinical diagnosis of active leprosy in suspects was performed by a trained health care worker and confirmed by a leprosy expert. Diagnosis followed the WHO guidelines ${ }^{11}$ by lesion assessment and nerve function test with discrimination between multibacillary (MB) cases and paucibacillary (PB) cases, according to the number of dermatological lesions. Additional data on grade 2 disability affecting the hands, feet and eyes were collected according to the WHO recommendation. The frequency of grade 1 disability was not recorded in this study. In leprosy, the appearance of a disability, including a degree 2 disability in WHO classification (visible disability) refers to late screening. This study only refers to grade 2 defects in hands and feet. It was difficult in the context of the investigation to assess the disabilities in the eyes and, in this case, to attribute them to leprosy. A family considered to have a history of leprosy is a family in which 1 or more cases of leprosy have been detected regardless of the relationship or age of the case or whether the case occurred within the village under consideration. Additionally, the family size was recorded which was defined by the average number of people sharing the living space or the bedroom in each household. 
Table 1. The demographic data, prevalence, leprosy diagnosis and leprosy classification of 1605 study participants in the two villages Koutal and Mballing in Senegal

\begin{tabular}{lccc}
\hline & Koutal & Mballing & Total \\
\hline Study participants $(n)$ & 671 & 934 & 1605 \\
Adults $(n(\%))$ & $384(57.2)$ & $522(55.9)$ & 906 \\
Children $(n(\%))$ & $287(42.8)$ & $412(44.1)$ & 699 \\
Leprosy newly diagnosed patients (no MDT yet) & & \\
Age (years) (median) & 23.6 & 17.2 & 20.4 \\
Active cases $(n)$ & 46 & 37 & 83 \\
Prevalence $(\%)$ & $6.9 \%$ & $4.0 \%$ & $5.2 \%$ \\
New cases adults $(n)$ & 18 & 10 & 28 \\
New cases child $(n)$ & 21 & 20 & 41 \\
New cases total $(n)$ & 39 & 30 & 69 \\
Case detection rate/100,000 & 5812 & 3212 & 4299 \\
MB adult $(n)^{*}$ & 4 & 1 & 5 \\
MB child $(n)^{*}$ & 2 & 3 & 5 \\
MB total $(n)^{*}$ & 6 & 4 & 10 \\
PB adult $(n)^{*}$ & 14 & 9 & 23 \\
PB child $(n)^{*}$ & 19 & 17 & 36 \\
PB total $(n)^{*}$ & 33 & 26 & 59 \\
Grade 2 disability $(n)$ & 1 & 1 & 2 \\
MB and PB according & & &
\end{tabular}

* MB and PB according to WHO clinical leprosy classification.

\section{METHOD OF ANALYSIS}

The data were encoded, entered into Microsoft Excel, analyzed by Epi-info 6 software on a descriptive and analytical level. The comparison of risk factors was done using the chi-square method or the Fisher test, with an agreed risk of 0.05 and an accuracy of 0.02 .

\section{Results}

\section{DEMOGRAPHIC DATA}

In Koutal, 671 people aged 5 years and above were examined, of whom 345 (51.4\%) were female and $326(48.6 \%)$ were male. The sample in Mballing was composed of 934 people, of whom $536(57.4 \%)$ were female and 398 (42.6\%) were male. Children between 5 and 15 constituted 42.8\% (287/671) of the population in Koutal and 44.1\% (412/934) in Mballing.

\section{HEALTH DATA}

\section{Prevalence of leprosy}

Altogether 83 cases of active leprosy were detected, 46 in Koutal and 37 in Mballing. Among the detected cases there were 69 new cases which had not yet been treated (Koutal 39 and Mballing 30). In each village, 7 (14 in total) additional cases were identified who had recently started MDT treatment.

The prevalence of leprosy in Koutal is therefore 6.9\% and in Mballing 4.0\%, altogether $5.2 \%$. The new case detection was 5812/100,000 in Koutal and 3212/100,000 in Mballing (see Table 1). 


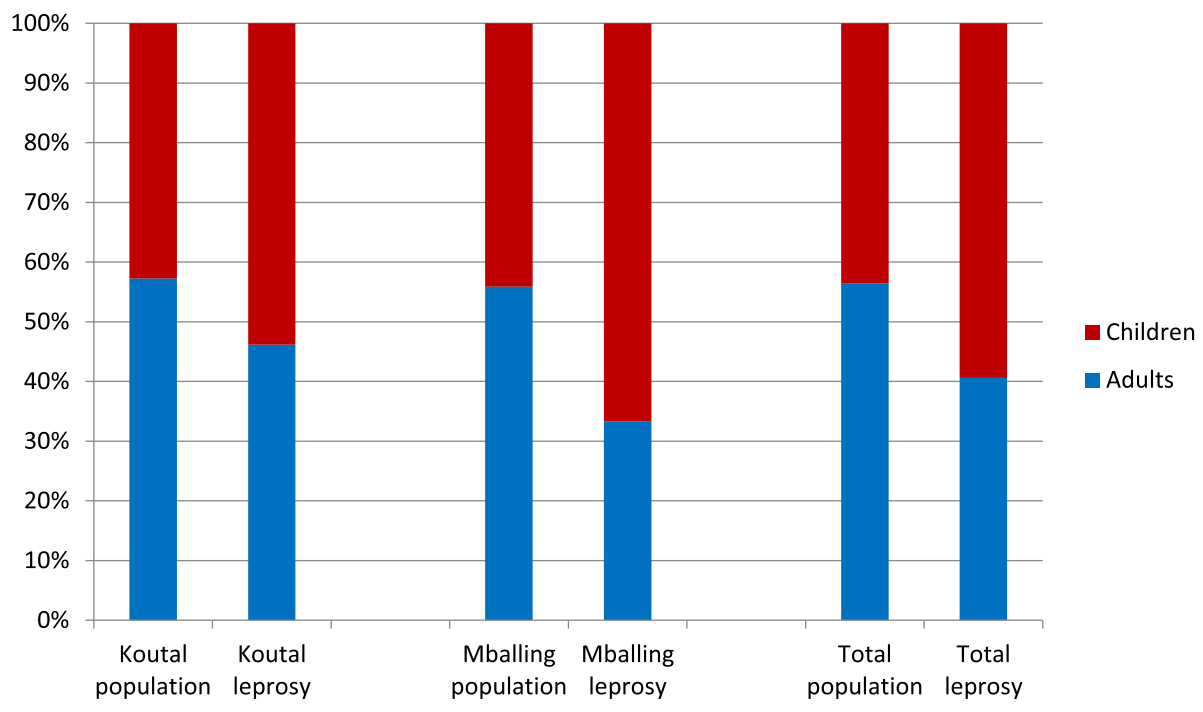

Figure 1 In two high endemic villages in Senegal children are most affected by leprosy.

\section{Characteristics of new cases of leprosy}

Forty one of the new cases were diagnosed in children (Koutal 21, Mballing 20) which is $59.4 \%$ of all new cases (see Figure 1). Thirty (43.5\%) of the new cases were female (Koutal 18, Mballing 12). The median age of new cases was 23.6 years in Koutal and 17.2 years in Mballing.

Among the new cases, 10 (14.5\%) were detected with multibacillary infection (MB). In Koutal, 6 (15.4\%) were MB, 2 of them were child cases, and in Mballing 4 (13.3\%) were MB form, 1 adult and 3 child cases. Amongst child cases, $87.8 \%$ presented as PB cases, while for adults the figure was $82.1 \%$.

In each village, 1 case of grade 2 disability was noted among the new patients detected. In Koutal, this was a 55-year-old woman with a foot-related disability, probably a plantar perforation in multibacillary leprosy. In terms of occurrence, the percentage of disability among the new cases was $2.6 \%$ in Koutal. In Mballing, a young man of 19 years presented with a visible disability of the hand, probably a cubital or cubitomedial claw. The percentage of disability among new cases is $3.3 \%$ in Mballing. The investigation did not go into more detail to specify the exact nature of the deficits.

\section{Cured leprosy cases}

During this study, 48 former leprosy patients were identified in Koutal and 55 in Mballing. All of them were treated in the past with MDT or dapsone monotherapy. Among the cases in Koutal, $12(25 \%)$ were free of all visible neurological damage, $36(75 \%)$ presented one or more neurological injuries of the eyes, hands or feet, including $13(27.1 \%)$ with triple mutilation of the eye, hand and foot. Among the 55 former, cured cases in the Mballing sample, 27 (49.1\%) were without visible neurological damage, 28 (50.9\%) showed one or more injuries, including $10(18.2 \%)$ with triple impairment of the eye, hand and foot. 
Table 2. Frequency of occurrence of leprosy according to the family history of leprosy in the two villages

\begin{tabular}{lccc}
\hline & Koutal & Mballing & Total \\
\hline Study participants $(n)$ & 671 & 934 & 1605 \\
Screened participants from families affected with leprosy & 322 & 468 & 790 \\
Screened participants from families not affected with leprosy & 349 & 466 & 815 \\
Newly diagnosed leprosy patients $(n)$ & 39 & 30 & 69 \\
New cases from families affected with leprosy & 19 & 25 & 44 \\
New cases from families not affected with leprosy & 20 & 5 & 25 \\
Relationaship between new leprosy cases and direct ancestors affected & & & \\
by leprosy $n=67$ (2 with missing information) & & 12 & 25 \\
New cases with mother or father affected & 13 & 12 & 15 \\
New cases with grandparents affected & 3 & 1 & 2 \\
New cases with other family members affected (husband, etc) & 1 & & \\
\hline
\end{tabular}

\section{Occurrence of the disease in families with a family history of leprosy}

Both study sites are in high leprosy endemic settings. It is therefore important to understand whether a source of contagion in the family plays a role in the infection.

Overall, 58\% of families in the study had a family history of leprosy, in Mballing 249 out of 421 families (59\%) and in Koutal 69 out of 128 families (53\%) had a history of leprosy.

Of the screened population, 790 were living in a family with history of leprosy (322 Koutal and 468 Mballing). Living in a family with a history of leprosy proved to be a statistically significant risk factor for leprosy infection. We found that, of 69 new cases, 44 came from families affected with leprosy, giving an odds ratio of 1.864 (95\% CI 1.129, 3.076) and a statistically significant difference ( $p$-value 0.0135 ). Additionally, having a direct ancestor in the first or second generation increases the risk (see Table 2).

\section{Discussion}

The high number of new cases detected during this study is directly associated with the mode of detection. In these villages, district records show that usually 5-6 cases are detected passively per year. In Koutal and Mballing, this study involved active case finding through whole body screening, which enabled the identification of 5 to 6 times more patients in both sites in a few days. Therefore, a high rate of hidden cases was present at the study sites. The prevalence of leprosy in the two villages was shown to be very high with $6.9 \%$ in Koutal and $4.0 \%$ in Mballing. For every 23 people screened, one new leprosy case was detected. However, the cases detected are mainly paucibacillary leprosy, especially in the children, who form the most important group of new cases.

The high prevalence shows that attempts to eliminate the infectious reservoir with MDT in both villages was not successful. Patients declared as "cured", after several decades of dapsone monotherapy, may not have received MDT despite recommendations, and may still carry leprosy bacteria.

The expression of the disease results from the interaction between the Mycobacterium leprae and the immune system of the infected host. While the vast majority of infected individuals develop effective immunity without clinical illness, some develop leprosy. The immunological status is genetically controlled ${ }^{12}$ and therefore genetic factors may influence the appearance of the disease. Studies of twins in the sixties indicated that leprosy has a genetic share and more recently, two major chromosomal regions have been identified through genetic 
linkage studies using complete genome screening. ${ }^{13-15}$ Genetic susceptibility to infectious diseases is no longer questioned. It is known that the type of clinical manifestation depends heavily on genetic factors. The concentration of highly susceptible individuals in the study area could be explained by the movement of people affected by leprosy into the villages and limited immigration by unaffected individuals. Such highly endemic areas cannot be compared to the general population in Senegal. A high percentage (49.1\%) of families who were screened in this study had at least one or more cases of leprosy reported in the last three generations.

The incidence of leprosy was significantly higher in subjects with a family history of leprosy and an almost 2-fold higher risk could be determined. This is lower than described in the literature where up to 8 -fold higher risks are mentioned. ${ }^{16}$ The study of the influence of "contact" in the appearance of leprosy is very complex. Contact with a person affected by leprosy can be assessed at two levels: a family contact (closer contact, more or less close contact, inside the family) or a social contact (more or less occasional contact outside the family). In the context of these highly isolated villages, with highly endemic leprosy, the family contact, assessed as previously described, seems to have a lower influence on the appearance of the disease than described elsewhere. One can imagine that the circulation of the germ is at a high level in each village, and sufficiently intense for family contact and social contact, such as previously described. Both ways of contacts might be quite identical and therefore play an almost equivalent role in the transmission of the disease, apart from other favorable factors which could include genetic susceptibility. The frequency of occurrence of the disease, specifically in families with a history of leprosy, is increasing when the contact is a direct ascendant (father or mother) or a second-generation ascendant (grandfather or grandmother). Intimate and prolonged contact is related to the narrowness of contact. The observed proximity between children, parents and grandchildren in Koutal and Mballing could be explained by a socio-economic approach and similarities, but especially differences were found in the way of accommodation between the two villages that could explain a higher incidence of leprosy in Koutal.

Until 2010, Senegal was one of the most successful African countries in the fight against leprosy: a 100\% coverage rate for patients with MDT since 1994 with completion rates in the order of 96 to $100 \%$ and a prevalence of the disease below the elimination threshold since 1995. However, as in most endemic countries the incidence is stable and requires measures to be taken as part of a global strategy to combat leprosy. Implementing active case finding by screening contacts of new cases and post exposure prophylaxis (PEP) with single dose rifampicin (SDR) is recommended by the $\mathrm{WHO}^{17}$ as a new tool to reduce leprosy transmission. Implementation of SDR-PEP must be well planned and therefore it is of utmost importance to further study the level of endemicity, spatial distribution and the epidemiological profile of leprosy in Senegal.

\section{Conclusions}

A high level of Mycobacterium leprae is circulating within the study population in two Senegalese communities that have existed for decades as "villages des reclassement social" or leprosy villages, isolated from surrounding communities. The epidemiological profile, especially the high number of children affected, suggests that transmission is ongoing. In addition to the influence of contact profile, genetic susceptibility to leprosy could explain high amount of familial leprosy cases in this special area, isolated for many years. There is a need for further implementation research to improve leprosy control, through measures such as post 
exposure prophylaxis with single dose rifampicin (recommended since 2018 by $\mathrm{WHO}^{17}$ ), to interrupt transmission.

\section{List of abbreviations}

- Multibacillary (MB)

- Multidrug therapy (MDT)

- Paucibacillary (PB)

- Post exposure prophylaxis (PEP)

- Single dose rifampicin (SDR)

- Villages des reclassement social (VRS)"

- World Health Organization (WHO).

\section{Declarations}

\section{Ethics approval and consent to participate}

Ethical clearance was approved by the Comité National d'Ethique pour la Recherche en Santé Senegal under certificate number no 103/MSAS/DPRS/CNERS.

\section{Consent for publication}

Not applicable.

\section{Availability of data and materials}

The datasets used and/or analyzed during the current study are available from the corresponding author on reasonable request.

\section{Competing interests}

The authors declare that they have no competing interests.

\section{Funding}

This study was funded by the DAHW own research funds.

\section{Authors' contributions}

IM, CK, AL, KP, HZ, MD, MC, designed the concept of the study MD, IM, FL, PD, AD, MC collected the data; IM, MD, MC, KP, CK conducted data analysis and wrote the manuscript.

\section{Acknowledgements}

We pay a vibrant post mortem tribute to Doctor-Colonel Ibrahima Mané, recalled to God at the end of his life which he dedicated to the well-being of people affected by leprosy. May God welcome him to the highest heaven.

Additional thanks go to Sène D, Dieng Sall W, Ndiaye M, Fall F, and Ngom K, from the Ministry of Health and Social Welfare, Senegal for their support and contribution to the success of this work. 


\section{References}

1 Robbins G, Tripathy VM, Misra VN, Mohanty RK, Shinde VS, Gray KM. Ancient skeletal evidence for leprosy in India (2000 B.C.). PLoS One, 2009; 4(5): e5669.

2 WHO. Global Leprosy Strategy 2016-2020: Accelerating towards a leprosy-free world [Internet]. WHO. [zitiert 3. Februar 2020]. Verfügbar unter: http://www.who.int/lep/resources/9789290225096/en/.

3 Mahé A. Leprosy is definitely not a disease of the past. Med Sci MS, 2015; 31(8-9): 764-769.

4 Niang SO, Diallo M, Ndiaye M, Diop A, Diatta BA, Wadih M. Epidemiologic and clinicopathologic aspects of Leprosy in Dakar; evaluation of 73 new cases. Dermatol Rep, 2011; 3(2): e18.

5 Diop MM, Berthe A, Diousse P, Mahamat Y, Fall L, Touré PS. La lèpre : quatre cas de retard tardif. Rev Afr Malgache Rech Sci Santé [Internet]. 1. April 2014 [zitiert 20. August 2019]; 1 (2). Verfügbar unter: http://publication.lecames.org/index.php/sante/article/view/96.

6 Dioussé P, Dione H, Bammo M, Gueye N, Diallo TAA, Seck F. La lèpre de l'enfant à Thiès/Sénégal: signal d'une recrudescence? Pan Afr Med J [Internet]. 5. Juli 2017 [zitiert 20. August 2019];27. Verfügbar unter: https://www.ncbi.nlm.nih.gov/pmc/articles/PMC5579445/.

7 Rosa PS, D’Espindula HRS, Melo ACL, Fontes ANB, Finardi AJ, Belone AFF. Emergence and Transmission of Drug-/Multidrug-resistant Mycobacterium leprae in a Former Leprosy Colony in the Brazilian Amazon. Clin Infect Dis Off Publ Infect Dis Soc Am, 2020; 70(10): 2054-2061.

8 WHO - Guidance note on using the cluster approach to strengthen humanitarian response [Internet]. WHO. [zitiert 25. August 2020]. Verfügbar unter: https://www.who.int/hac/network/interagency/news/ cluster_approach/en/.

9 Godelier M. Le travail et ses représentations. J Anthropol, 1981; 5(1): 10-14.

10 Agence Nationale de Statistique et de la Démographie [Internet]. [zitiert 3. Februar 2020]. Verfügbar unter: http://www.ansd.sn/.

11 WHO WH. Global strategy for further reducing the leprosy burden and sustaining leprosy control activities (2006-2010) : Operational Guidelines. 2006 [zitiert 3. Februar 2020]; Verfügbar unter: [https://apps.who.int/ iris/handle/10665/205142.

12 Alcaïs A, Mira M, Casanova J-L, Schurr E, Abel L. Genetic dissection of immunity in leprosy. Curr Opin Immunol, 2005; 17(1): 44-48.

13 Yang Q, Liu H, Low H-Q, Wang H, Yu Y, Fu X. Chromosome 2p14 is linked to susceptibility to leprosy. PLoS One, 2012; 7(1): e29747.

14 Mira MT, Alcaiis A, Van Thuc N, Thai VH, Huong NT, Ba NN. Chromosome 6q25 is linked to susceptibility to leprosy in a Vietnamese population. Nat Genet März, 2003; 33(3): 412-415.

15 Sauer MED, Salomão H, Ramos GB, D’Espindula HRS, Rodrigues RSA, Macedo WC. Genetics of leprosy: Expected-and unexpected-developments and perspectives. Clin Dermatol, 2016; 34(1): 96-104.

16 Moet FJ, Pahan D, Schuring RP, Oskam L, Richardus JH. Physical distance, genetic relationship, age, and leprosy classification are independent risk factors for leprosy in contacts of patients with leprosy. J Infect Dis, 2006; 193(3): 346-353.

17 WHO - Guidelines for the diagnosis, treatment and prevention of leprosy [Internet]. WHO. [zitiert 28. Oktober 2020]. Verfügbar unter: http://www.who.int/lep/resources/9789290226383/en/. 